\title{
USO DE RESÍDUOS DA INDÚSTRIA DE LATICÍNIOS COMO MEIO DE CULTURA ALTERNATIVO PARA CRESCIMENTO DE LACTOBACILLUS
}

\author{
Michel A. Amaral ${ }^{1 *}$, Adriano G. Parreira², Paulo A. Granjeiro², Juliana T. \\ Magalhães $^{1}$ \\ ${ }^{1}$ Laboratório de Microbiologia, Universidade Federal de São João Del-Rei, Divinópolis/MG \\ ${ }^{2}$ Laboratório de Processos Biotecnológicos e Purificação de Macromoléculas, Universidade Federal de São João Del-Rei, \\ Divinópolis/MG \\ *e-mail: michel.amaral.mg@gmail.com
}

\section{Resumo}

Lactobacillus são bactérias conhecidas pelo potencial probiótico, são fastidiosas e requerem meios complexos com elevados níveis de nutrientes. Por isso, alguns estudos otimizam os processos a partir de substratos alternativos, já que muitas substancias de interesse industrial, possuem baixo rendimento. Um substrato em potencial é o soro de laticínios, uma vez que é composto por níveis elevados de nutrientes, além de ser um produto residual que representa um grande problema ambiental. Neste sentido, este trabalho teve como objetivo avaliar o cultivo de Lactobacillus em meio alternativo contendo resíduos da industria de laticínios. Quatro tipos de meios de cultura foram testados: (1) o soro desproteinado: o soro teve seu $\mathrm{pH}$ ajustado para 4,5 , foi autoclavado a $121^{\circ} \mathrm{C}$, os precipitados foram removidos por centrifugação e o $\mathrm{pH}$ do sobrenadante ajustado a 6,3 e esterilizado a $121^{\circ} \mathrm{C}$ por $15 \mathrm{~min}$; (2) soro enriquecido: no soro foram adicionados extrato de leveduras $(3 \mathrm{~g} / \mathrm{L})$ e peptona $(10 \mathrm{~g} / \mathrm{L})$; (3) soro cru esterrilizado e (4) o meio de cultura MRS. Uma colônia da bactéria Lactobacillus P2, isolado no Laboratório de Microbiologia da UFSJ, foi inoculada em cada um dos meios e a incubação foi a $37^{\circ} \mathrm{C}$ por $48 \mathrm{~h}$. Após este período, alíquotas foram plaqueadas em ágar MRS e as placas incubadas a $37^{\circ} \mathrm{C}$. O número de $\mathrm{UFC} / \mathrm{ml}$ foi calculado. Os resultados foram analisados com o teste estatístico de Kruskal-Wallis para análise da variância entre os valores encontrados em cada um dos meios. $\mathrm{O}$ resultado foi um $p$-valor de 0,1038 com grau de liberdade 3 , mostrando que não houve diferença significativa entre os resultados, no que diz respeito ao crescimento microbiano (UFC/ml). Os resultados indicam que o soro de 
laticínios pode ser utilizado como meio alternativo ao MRS sem comprometimento do crescimento bacteriano, podendo reduzir consideravelmente os custos para os estudos de produção de produtos de interesse associados ao crescimento de Lactobacillus.

Palavras-chave: Lactobacillus, soro de laticínios, crescimento

Apoio financeiro: CNPq, FAPEMIG. 